\title{
Calculation of Energy Levels and The Reduced Transitions Probability For Even-Even Number of Isotones ( $\mathbf{N}=90)$
}

\author{
Ahmad K. Mheemeed \\ Departmen of Physics / College of Education \\ University of Mosul
}

Received

07 / 12 / 2007
Accepted

03 / 03 / 2008

\begin{abstract}
In this work the Interacting Boson Model IBM-1, DavydovFilippov (D-F) models and the Critical Point Symmetry X(5) have been employed to study the energy levels and the reduced transition probability $\mathrm{B}(\mathrm{E} 2)$ for the $(\mathrm{N}=90)$ transitional nuclei ${ }^{146} \mathrm{Ba},{ }^{148} \mathrm{Ce},{ }^{158} \mathrm{Er}$ and ${ }^{160} \mathrm{Yb}$ in the concepts of theoretical treatment. The best input parameters for the above approaches which lead to the best fit to experimental data are determined. The reduced transition probability B(E2) for the above nuclei have been calculated in a relative and absolute scales by using the most recent available experimental data.
\end{abstract}

\section{الخالصة}

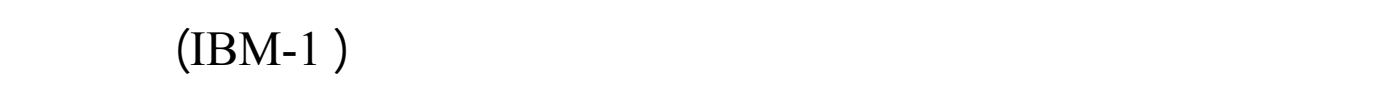
دافيدوف و فيليبوف ( D-F) و أنموذج تنظظر النظة الحرجة (5) Eمسلب مستويلت الطاقة

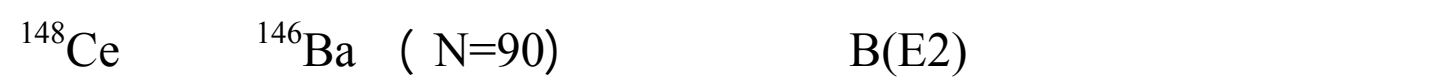
و

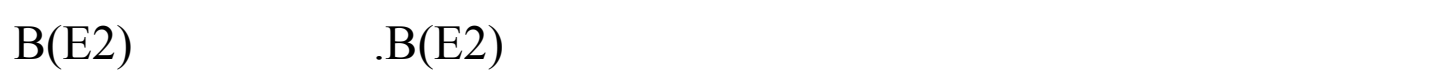
الهلقة و النسبية للوى أعلاه ولستخمت في هذه الحسابت البيانت العملية الحيثة. 


\section{1- Introduction}

The structure of the $\mathrm{N}=90$ isotones in the vicinity of the $\mathrm{Z}=64$ has been the focal point of a research groups. A rapid change in deformation occurs at $\mathrm{N} \approx 90$ nuclei, a long the $\mathrm{Nd}, \mathrm{Sm}, \mathrm{Gd}$ and $\mathrm{Dy}$ isotopic chains, as a transition occurs from spherical to axially deformed structure (1-5). The study of phase-shape transitions in nuclei can be done in the interacting boson model (IBM) which reproduces well the data in the transitional Nd-Sm-Gd-Dy region $(3,6-8)$. Recently a new symmetry, called X(5), has been proposed for the critical point of phase-shape transition from spherical to axially deformed nuclei (2-4). The $\mathrm{N}=90$ isotones ${ }^{150} \mathrm{Nd}$ and ${ }^{152} \mathrm{Sm}$ are a good example of the realization of this symmetry $(1,3,5,9,10)$. Additional examples of $\mathrm{X}(5)$ behaviors have been suggested in $\mathrm{N}=90$ isotones ${ }^{154} \mathrm{Gd}$ and ${ }^{156} \mathrm{Dy}(3,11)$.

The aim of the present work is to apply the interacting boson model (IBM-1), the Davydov-Fillipov model and the critical point symmetry $\mathrm{X}(5)$ for calculating the values of the energy levels and the reduced electric quadrupole transition probability $\mathrm{B}(\mathrm{E} 2)$ for the other $\mathrm{N}=90$ transitional nuclei, ${ }^{146} \mathrm{Ba},{ }^{148} \mathrm{Ce},{ }^{158} \mathrm{Er}$ and ${ }^{160} \mathrm{Yb}$, lying between the $\mathrm{SU}(5)$ and SU (3) limits.

\section{2- Nuclear Models}

\section{2-1 The Interacting Boson Model -1 (IBM-1)}

The Interacting Boson Model of Arima and Iachello (12-17) ,has widely accepted as a tractable theoretical scheme of correlating, describing and predicting low-energy collective properties of complex nuclei. The most general Hamiltonian subject to the conditions of U(6) symmetry can be written as $(15,17)$.

$$
\hat{H}=\varepsilon \hat{n}_{d}+a_{o} \hat{P} \cdot \hat{P}+a_{1} \hat{L} \cdot \hat{L}+a_{2} \hat{Q} \cdot \hat{Q}+a_{3} \hat{T}_{3} \cdot \hat{T}_{3}+a_{4} \hat{T}_{4} \cdot \hat{T}_{4}
$$

where $\varepsilon$ is the energy of boson. For the simplest form (which is $\varepsilon=\varepsilon_{\mathrm{d}}-\varepsilon_{\mathrm{s}}$, assuming $\left.\varepsilon_{\mathrm{s}}=0\right) . \quad n_{d}$ is the operator of the d-boson number.

$a_{0}, a_{1}, a_{2}, a_{3}, a_{4}$ parameters represent the strength of the pairing, angular momentum, quadrupole, octupole and hexadecapole interactions respectively. $\hat{P}, \hat{L}, Q, T_{3}$ and $T_{4}$ represents the operators for each interaction respectively. For the transition case between $\mathrm{SU}(5)$ and $\mathrm{SU}(3)$ limits, the above Hamiltonian reduced to

$$
\hat{H}=\varepsilon \hat{n}_{d}+a_{1} \hat{L} \cdot \hat{L}+a_{2} \hat{Q} \cdot \hat{Q}
$$

In order to calculate electromagnetic transition rates, one must specify the transition operators. The (E2) transition operator can be written as $(7,15)$. 


$$
\mathrm{T}_{\mu}^{(\mathrm{E} 2)}=\alpha_{2}\left[\hat{\mathrm{d}}^{\dagger} \times \hat{\widetilde{\mathrm{s}}}+\hat{\mathrm{s}}^{\dagger} \times \hat{\tilde{\mathrm{d}}}\right]_{\mu}^{(2)}+\beta_{2}\left[\hat{\mathrm{d}}^{\dagger} \times \hat{\tilde{\mathrm{d}}}\right]_{\mu}^{(2)}
$$

where $\alpha_{2}$ plays the role of the effective boson charge and $\beta_{2}$ is a parameter related to $\alpha_{2}$. The parameter $\alpha_{2}$ is related to the reduced transition probability $\mathrm{B}(\mathrm{E} 2)$ as follows:

1- For SU(5) limit $(7,15)$

$\mathrm{B}(\mathrm{E} 2 ; \mathrm{L}+2 \rightarrow \mathrm{L})=\alpha_{2}^{2} \frac{1}{4}(\mathrm{~L}+2)(2 \mathrm{~N}-\mathrm{L})$

This gives, for the first $2^{+}$state.

$$
\mathrm{B}\left(\mathrm{E} 2 ; 2_{1}^{+} \rightarrow 0_{1}^{+}\right)=\alpha_{2}^{2} \mathrm{~N}
$$

2- For SU(3) limit $(7,15)$

$$
\mathrm{B}(\mathrm{E} 2 ; \mathrm{L}+2 \rightarrow \mathrm{L})=\alpha_{2}^{2} \frac{3(\mathrm{~L}+2)(\mathrm{L}+1)}{4(2 \mathrm{~L}+3)(2 \mathrm{~L}+5)}(2 \mathrm{~N}-\mathrm{L})(2 \mathrm{~N}+\mathrm{L}+3)
$$

Or $\quad \mathrm{B}\left(\mathrm{E} 2 ; 2_{1}^{+} \rightarrow 0_{1}^{+}\right)=\alpha_{2}^{2} \frac{1}{5} \mathrm{~N}(2 \mathrm{~N}+3)$

\section{2-2 Davydov and Filippovs (D-F) Model}

Rotational levels of even-even nuclei have been treated by Davydov-Filippov and Rostovsky (18-20) under the assumption that the nuclei possesses equilibrium shapes which are not axially symmetric. The formulae for levels with spins $2^{+}$and $3^{+}$are $(18,21,22)$.

$$
\begin{aligned}
& \mathrm{E}\left(2_{1}\right)=\frac{3(3-\mathrm{x})}{\mathrm{y}} \\
& \mathrm{E}\left(2_{2}\right)=\frac{3(3+x)}{\mathrm{y}} \\
& \mathrm{E}\left(3_{1}\right)=\frac{18}{\mathrm{y}}
\end{aligned}
$$

Where $x=\sqrt{9-8 \sin ^{2}(3 \gamma)}$

$$
\text { Then } \begin{aligned}
\mathrm{X} & =\sin ^{2}(3 \gamma) \\
\gamma & =\sqrt{9-8 \mathrm{y}} \\
\gamma & =\frac{1}{3} \sin ^{-1} \sqrt{y}
\end{aligned}
$$

$\gamma$ is the asymmetrical parameter which is determine the deviation of the shapes of the nucleus from axially symmetry. The quantity $\gamma$ can easily be determined from the ratio of the energies of two levels with angular momenta $\mathrm{I}=2$. 


$$
\frac{E 2_{2}}{E 2_{1}}=\frac{(3+x)}{(3-x)}
$$

and the relations (13) and (14).

The equations for levels with spins $4+, 6+$, and $8+$ are the roots of the third, fourth and fifth degree respectively $(19,21,22)$. Results of numerical solutions of these equations for several values of $\gamma$ are given in ref.(19). These equations are not used in the present work; instead the graphical method has been used (see section 3-1-2).

The formulae for the transition probabilities $b(E 2)$ are (18,21-23)

$$
\begin{aligned}
& b\left(E 2 ; 2_{1}^{+} \rightarrow 0_{1}^{+}\right)=\frac{(x-2 y+3)}{2 x} \\
& b\left(E 2 ; 2_{2}^{+} \rightarrow 0_{1}^{+}\right)=\frac{(x+2 y-3)}{2 x} \\
& b\left(E 2 ; 2_{2}^{+} \rightarrow 2_{1}^{+}\right)=\frac{10 y}{7 x^{2}} \\
& b\left(E 2 ; 3_{1}^{+} \rightarrow 2_{1}^{+}\right)=\frac{25(x+2 y-3)}{28 x} \\
& b\left(E 2 ; 3_{1}^{+} \rightarrow 2_{2}^{+}\right)=\frac{25(x-2 y+3)}{28 x}
\end{aligned}
$$

The transition probabilities $b\left(E 2 ; 4_{1}^{+} \rightarrow 2_{1}^{+}\right), b\left(E 2 ; 4_{2}^{+} \rightarrow 2_{2}^{+}\right), b\left(E 2 ; 4_{2}^{+} \rightarrow 4_{1}^{+}\right)$, $b\left(E 2 ; 3_{1}^{+} \rightarrow 4_{1}^{+}\right), b\left(E 2 ; 6_{1}^{+} \rightarrow 4_{1}^{+}\right)$, can be calculated by using the relations and the wave function coefficient given by $(D-F)(19,22)$. The values of these transition probabilities for several $\gamma$ values are given by (D-F) (19). In the present work, the graphic method has been used between $b(E 2)$ and $\gamma$ to calculate the above $b(E 2)$ (see section 3-2-3). The relation between the reduced Electric transition probability $\mathrm{B}(\mathrm{E} 2)$ and the transition probability $\mathrm{b}(\mathrm{E} 2)$ is $(18)$.

$\mathrm{B}\left(\mathrm{E} 2 ; 2_{1}^{+} \rightarrow 0_{1}^{+}\right)=\frac{\mathrm{e}^{2} \mathrm{Q}_{0}^{2}\left(\mathrm{~b}^{2}\right)}{16 \pi} \mathrm{b}\left(\mathrm{E} 2 ; 2_{1}^{+} \rightarrow 0_{1}^{+}\right)$

Where $\mathrm{Q}_{0}$ is the intrinsic quadrupole moment.

\section{2-3 Critical Point Symmetry X(5)}

Iachello introduced new dynamical symmetries at the critical point of a phase/shape transitions: $\mathrm{E}(5)$ for a transition between spherical and deformed $\gamma$-soft nuclei (24) and X(5) for transition between spherical and axially deformed nuclei $(2,3)$. His approach was based on analytical solutions of the differential equation for a geometrical (Bohr) 
Hamiltonian with a flat-bottomed potential in the quadrupole deformation. In the $X(5)$ model an infinite square well potential in $\beta$, $\mathrm{V}(\beta)$, is combined with a term $\mathrm{V}(\gamma)(3,5)$ :

$$
\begin{aligned}
& \mathrm{V}(\beta, \gamma)=\mathrm{V}(\beta)+\mathrm{V}(\gamma) \\
& \mathrm{V}(\beta)=\left\{\begin{array}{cc}
0, & \beta \leq \beta_{\mathrm{W}} \\
\infty, & \beta>\beta_{\mathrm{W}}
\end{array}\right\}
\end{aligned}
$$

The potential $\mathrm{V}(\gamma)$ is assumed to be harmonic around $\gamma_{0}$ with

$$
\mathrm{V}(\gamma)=1 / 2 \mathrm{C}\left(\gamma-\gamma_{0}\right)^{2}
$$

Where $\beta$ is the deformation parameter and $\gamma$ describing the deviation from axially symmetry.

The present $X(5)$ results for the energies of the ground-state band, $\beta$-band and $\gamma$-band are shown in Table (1) where the energies are normalized to $\mathrm{E} 2{ }_{1}{ }^{+}=1.0(3,5)$.

Table(1): Excitation energies predicted in the $\mathrm{X}(5)$ model $(3,5)$

\begin{tabular}{|c|c|c|c|c|c|c|c|c|c|c|c|c|c|}
\hline $\mathbf{J}^{\pi}$ & $0_{1}{ }^{+}$ & $2_{1}{ }^{+}$ & $4_{1}{ }^{+}$ & $6_{1}{ }^{+}$ & $8_{1}{ }^{+}$ & $0_{2}{ }^{+}$ & $2_{2}{ }^{+}$ & $4_{2}{ }^{+}$ & $6_{2}{ }^{+}$ & $2_{3}{ }^{+}$ & $3_{1}{ }^{+}$ & $4_{3}{ }^{+}$ & $5_{1}{ }^{+}$ \\
\hline $\begin{array}{c}\text { Energy } \\
\text { Level }\end{array}$ & 0.0 & 1.0 & 2.904 & 5.43 & 8.483 & 5.65 & 7.45 & 10.69 & 14.75 & 10.0 & 10.94 & 12.04 & 13.27 \\
\hline
\end{tabular}

$\mathrm{B}(\mathrm{E} 2)$ values for selected transitions predicted in the $\mathrm{X}(5)$ model are summarized in Figure $(1)(3,5)$. The values are normalized to the transition $\mathrm{B}\left(\mathrm{E} 2,2_{1}{ }^{+} \rightarrow 0_{1}^{+}\right)=100$. 


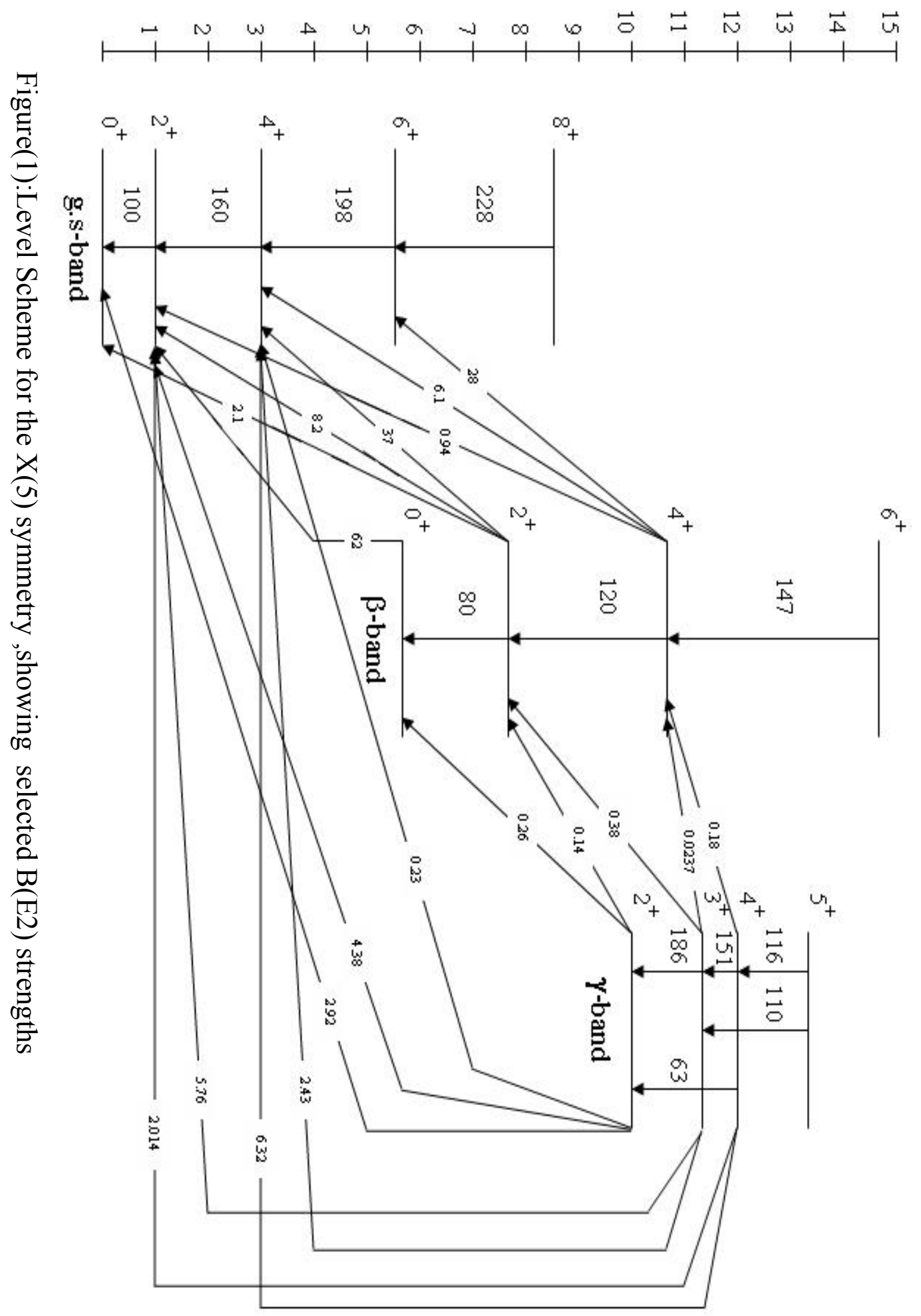




\section{3-Calculations}

\section{3-1 Energy Levels}

\section{3-1-1 IBM-1 Model}

The experimental energy ratio between the $\mathrm{E} 4_{1}{ }^{+}$and $\mathrm{E} 2{ }_{1}{ }^{+}$levels of the ground state band $\left(\mathrm{R}_{4 / 2}\right)$ for even-even ${ }_{56}^{146} \mathrm{Ba},{ }_{58}^{148} \mathrm{Ce},{ }_{68}^{158} \mathrm{Er}$ and ${ }_{70}^{160} \mathrm{Yb}$ nuclei are 2.83,2.87,2.74 and 2.63 respectively (25). It is clear from these values that the above nuclei have the properties between $\mathrm{SU}(5)\left(\mathrm{R}_{4 / 2}=2.0\right)$ and $\mathrm{SU}(3)$ limits $\left(\mathrm{R}_{4 / 2}=3.33\right)$.

The IBM-1 has been used in the calculation of the energy spectra. The program PHINT (IBM- code) written in FORTRAN 77 language has been used in the calculations (26). The number of bosons and the best values of the Hamiltonian parameters which gives the best fitting between theoretical and experimental energy levels of the above nuclei are shown in Table (2) .The $0_{2}^{+}$state ( $\beta$-band head) of the above nuclei is below the $2_{2}^{+}$state except for ${ }^{160} \mathrm{Yb}$. The term $\left(\mathrm{a}_{\mathrm{o}} \hat{P} \cdot \hat{P}\right)$ has been added to equation (2) in order to raise the $0_{2}^{+}$state. This term can describe nuclei in which the $\beta$-band lie above the $\gamma$-band in energy (17).

Table (2): The Parameters Used in IBM-1 Model and the Number of Bosons for ${ }^{146} \mathrm{Ba},{ }^{148} \mathrm{Ce},{ }^{158} \mathrm{Er}$ and ${ }^{160} \mathrm{Yb}$ nuclei.

\begin{tabular}{|c|c|c|c|c|c|c|c|c|c||}
\hline Nuclei & $\mathrm{N}$ & $\begin{array}{c}\varepsilon \\
\mathrm{MeV}\end{array}$ & $\begin{array}{c}\mathrm{a}_{0} \\
\mathrm{MeV}\end{array}$ & $\begin{array}{c}\mathrm{a}_{1} \\
\mathrm{MeV}\end{array}$ & $\begin{array}{c}\mathrm{a}_{2} \\
\mathrm{MeV}\end{array}$ & $\mathrm{CHI}$ & $\mathrm{SO}(6)$ & $\begin{array}{c}\text { E2SD } \\
(\mathrm{eb})\end{array}$ & $\begin{array}{c}\mathrm{E} 2 \mathrm{DD} \\
(\mathrm{eb})\end{array}$ \\
\hline \hline${ }^{146} \mathrm{Ba}$ & 7 & 0.25 & 0.0 & 0.0095 & -0.03 & -1.323 & 1.0 & 0.1093 & -0.1425 \\
\hline${ }^{148} \mathrm{Ce}$ & 8 & 0.15 & 0.0 & 0.0125 & -0.019 & -1.323 & 1.0 & 0.116 & -0.152 \\
\hline${ }^{158} \mathrm{Er}$ & 11 & 0.25 & 0.0 & 0.017 & -0.0135 & -1.323 & 1.0 & 0.1135 & -0.1476 \\
\hline${ }^{160} \mathrm{Yb}$ & 10 & 0.45 & 0.055 & 0.017 & -0.013 & -1.323 & 1.0 & 0.1152 & -0.1504 \\
\hline
\end{tabular}




\section{3-1-2 D-F Model}

The energy levels of even-even ${ }^{146} \mathrm{Ba},{ }^{148} \mathrm{Ce},{ }^{158} \mathrm{Er}$ and ${ }^{160} \mathrm{Yb}$ nuclei possessing spins 2 and 3 have been calculated by using equations (8),(9) and (10) .The results for numerical solutions of the equations for levels with spins 4,6 and 8 for several values of $\gamma$ have been taken from (19) and replotted as shown in Figure(2)

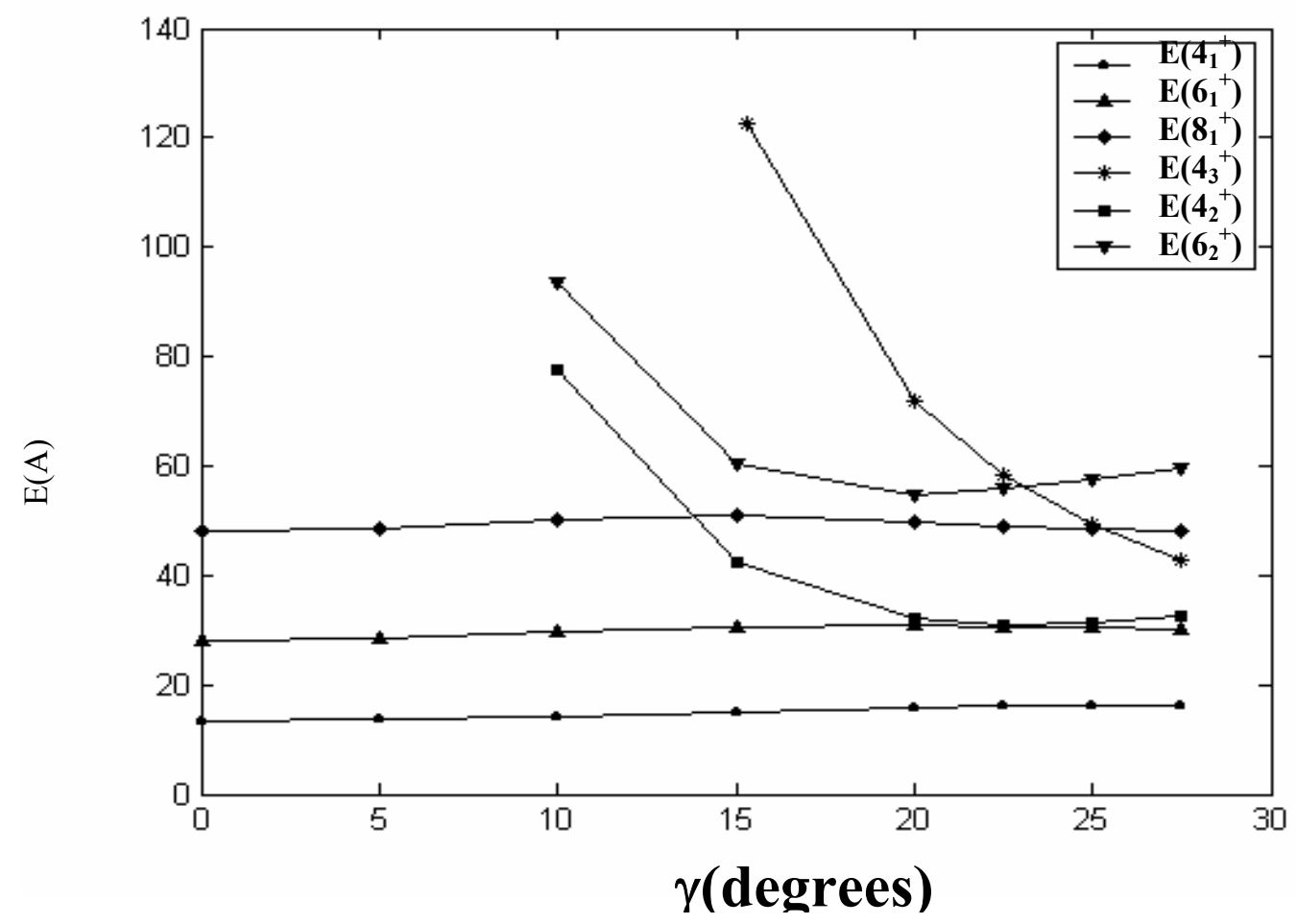

Fig. (2): The Computed Energy levels $\left(4_{1}{ }^{+}, 6_{1}{ }^{+}, 4_{2}{ }^{+}, 6_{2}{ }^{+}, 4_{3}{ }^{+}, 8_{1}{ }^{+}\right)$for Various Values of $(\gamma)$.

These plots are analyzed by using the MATLAB program to obtain the values of energy levels for ${ }^{146} \mathrm{Ba},{ }^{148} \mathrm{Ce},{ }^{158} \mathrm{Er}$ and ${ }^{160} \mathrm{Yb}$ nuclei from knowing their $\gamma$-values. The energy levels and $\gamma$-values the above nuclei are listed in Table (3).The constant (A) has the same energy dimension.

Table (3): Values of a Symmetry parameter $(\gamma)$ and Energy Levels for ${ }^{146} \mathrm{Ba},{ }^{148} \mathrm{Ce},{ }^{158} \mathrm{Er}$ and ${ }^{160} \mathrm{Yb}$ nuclei.

\begin{tabular}{|c|c|c|c|c|c|c|c|c|}
\hline \multirow{2}{*}{ Nucleus } & \multicolumn{8}{|c|}{$\mathrm{E}(\mathrm{A})$} \\
\hline & $\gamma$ & $2_{1}^{+}$ & $2_{2}^{+}$ & $3_{1}^{+}$ & $4_{1}^{+}$ & $6_{1}^{+}$ & $4_{2}^{+}$ & $8_{1}^{+}$ \\
\hline${ }^{146} \mathrm{Ba}$ & 15.778 & 4.649 & 28.641 & 33.290 & 15.157 & 30.808 & 40.020 & 50.690 \\
\hline${ }^{148} \mathrm{Ce}$ & 16.081 & 4.676 & 27.671 & 32.347 & 15.215 & 30.851 & 39.161 & 50.618 \\
\hline${ }^{158} \mathrm{Er}$ & 18.759 & 4.937 & 21.083 & 26.019 & 15.656 & 30.894 & 33.694 & 49.932 \\
\hline${ }^{{ }^{160} \mathrm{Yb}}$ & 20.992 & 5.185 & 17.498 & 22.683 & 15.908 & 30.668 & 31.512 & 49.335 \\
\hline
\end{tabular}




\section{3-1-3 Critical Point Symmetry X(5)}

A nucleus with an $\mathrm{R}_{4 / 2}$ value near 2.91 in a known spherical to axially deformed transition region is immediately of interest as a prospective $\mathrm{X}(5)$ nucleus $(2,3,5,11)$. The ${ }^{146} \mathrm{Ba},{ }^{148} \mathrm{Ce},{ }^{158} \mathrm{Er}$ and ${ }^{160} \mathrm{Yb}$ nuclei are constitute an example of such spherical to axially deformed transition region. We used the critical point symmetry $X(5)$ to calculate the energy levels of the above nuclei. The energy levels from X(5) [see Table (1)] are fitted to the first experimental excited state with spin $2\left(\mathrm{E} 2{ }_{1}{ }^{+}\right)$of the above nuclei and determined the other energy levels by using the conversion constant. This constant was calculated by dividing the $\left(\mathrm{E} 2_{1}{ }^{+}\right)_{\exp }$ from ref.(25) by the corresponding value obtained from critical point symmetry $\left.(\mathrm{E} 2)_{1}\right)_{\text {theo. }}$.

\section{3-2 The Reduced Transition Probability.}

\section{3-2-1 The Experimental Reduced Transition Probability.}

The absolute experimental reduced transition probability $\mathrm{B}(\mathrm{E} 2)$ $\left[\mathrm{e}^{2} \mathrm{~b}^{2}\right]$ values for the ${ }^{146} \mathrm{Ba},{ }^{148} \mathrm{Ce},{ }^{158} \mathrm{Er}$ and ${ }^{160} \mathrm{Yb}$ nuclei were calculated from available experimental data of; $\mathrm{T}_{1 / 2}, \mathrm{E} \gamma, \mathrm{I} \gamma, \alpha_{\mathrm{tot}}$, multipolarity and $\delta$ mixing ratio reported in refs.(27-31) and by making use the following equation $(21,32)$

$$
\mathrm{B}(\mathrm{E} 2)=\frac{0.05657}{\mathrm{~T}_{1 / 2}^{\gamma}(\mathrm{ps}) \mathrm{E}_{\gamma}^{5}(\mathrm{MeV})} \quad \text { in unit of }\left(\mathrm{e}^{2} \mathrm{~b}^{2}\right) \quad \ldots \ldots
$$

For states with unknown half-life, the relative values of $\mathrm{B}(\mathrm{E} 2)$ were given in relative scale, where the maximum $B(E 2)$ values was equated to 1.0 , relative $\mathrm{B}(\mathrm{E} 2)$ values then have been calculated from the relation

$$
\mathrm{B}(\mathrm{E} 2) \propto \frac{\mathrm{I}_{\gamma}(\mathrm{E} 2)}{\mathrm{E}_{\gamma}^{5}}
$$

\section{3-2-2 IBM-1.}

The reduced transition probability $\mathrm{B}(\mathrm{E} 2)$ calculations were carried out by using the computer program FBEM (IBMT- code)(26). The parameters used in this program namely E2SD and E2DD were determined for each ${ }^{146} \mathrm{Ba},{ }^{148} \mathrm{Ce},{ }^{158} \mathrm{Er}$ and ${ }^{160} \mathrm{Yb}$ nuclei according to this method:

$$
\begin{aligned}
& \mathrm{E} 2 \mathrm{SD}=\alpha_{2} \\
& \mathrm{E} 2 \mathrm{DD}=\beta_{2}
\end{aligned}
$$

The parameter $\alpha_{2}$ is calculated from the experimental value of $\mathrm{B}\left(\mathrm{E} 2 ; 2_{1}{ }^{+} \rightarrow 0_{1}{ }^{+}\right)$using equations (5) and (7) for $\mathrm{SU}(5)$ and $\mathrm{SU}(3)$ limits to 
get two values. The parameter $\beta_{2}$ is calculated from $\alpha_{2}$ for $\mathrm{SU}(5)$ limit by using the relation (16):

$0>\frac{\beta_{2}}{\alpha_{2}}>\left(-\frac{\sqrt{7}}{2}=-1.323\right)$

$\frac{\beta_{2}}{\alpha_{2}}=-1.323$ for $\mathrm{SU}(3)$ limit (15-17)

By taking the average of the two values for each $\alpha_{2}$ and $\beta_{2}$ parameters and slightly change the average values in order to get a good agreement between theoretical and experimental B(E2) values. The values of E2SD and E2DD for the above nuclei are listed in Table (2).

\section{3-2-3 D-F Model.}

The reduced probabilities for electric quadrupole transitions $b(E 2)$ for the transitions $2_{1}{ }^{+} \rightarrow 0_{1}{ }^{+}, 2_{2}{ }^{+} \rightarrow 0_{1}{ }^{+}, 2_{2}{ }^{+} \rightarrow 2{ }_{1}{ }^{+}, 3_{1}{ }^{+} \rightarrow 2_{1}{ }^{+}$and $3_{1}{ }^{+} \rightarrow 2_{2}{ }^{+}$have been calculated by using equations (16),(17),(18),(19)and (20) respectively. The $b(E 2)$ equations for transitions between levels with spins $(4,2),(4,4)$, and $(6,4)$ were presented by $(19,21,22)$. These equations are difficult for applications because the coefficients $A_{k}$ and $B_{k}$ for wave functions of the above states are required. Therefore, instead of these equations, we will apply a graphic method. The $b(E 2)$ values for the transitions $4_{1}{ }^{+} \rightarrow 2_{1}{ }^{+}, 3_{1}{ }^{+} \rightarrow 4_{1}{ }^{+}, 4_{2}{ }^{+} \rightarrow 2_{2}{ }^{+}, 4_{2}{ }^{+} \rightarrow 4_{1}{ }^{+}$and $6_{1}{ }^{+} \rightarrow 4_{1}{ }^{+}$for several values of $\gamma$ have been taken from (19) and replotted as shown in Figures (3), and (4). These plots were analyzed using the Matlab program to obtain the $b(\mathrm{E} 2)$ values for ${ }^{146} \mathrm{Ba},{ }^{148} \mathrm{Ce},{ }^{158} \mathrm{Er}$ and ${ }^{160} \mathrm{Yb}$ nuclei from their $\gamma$ values.

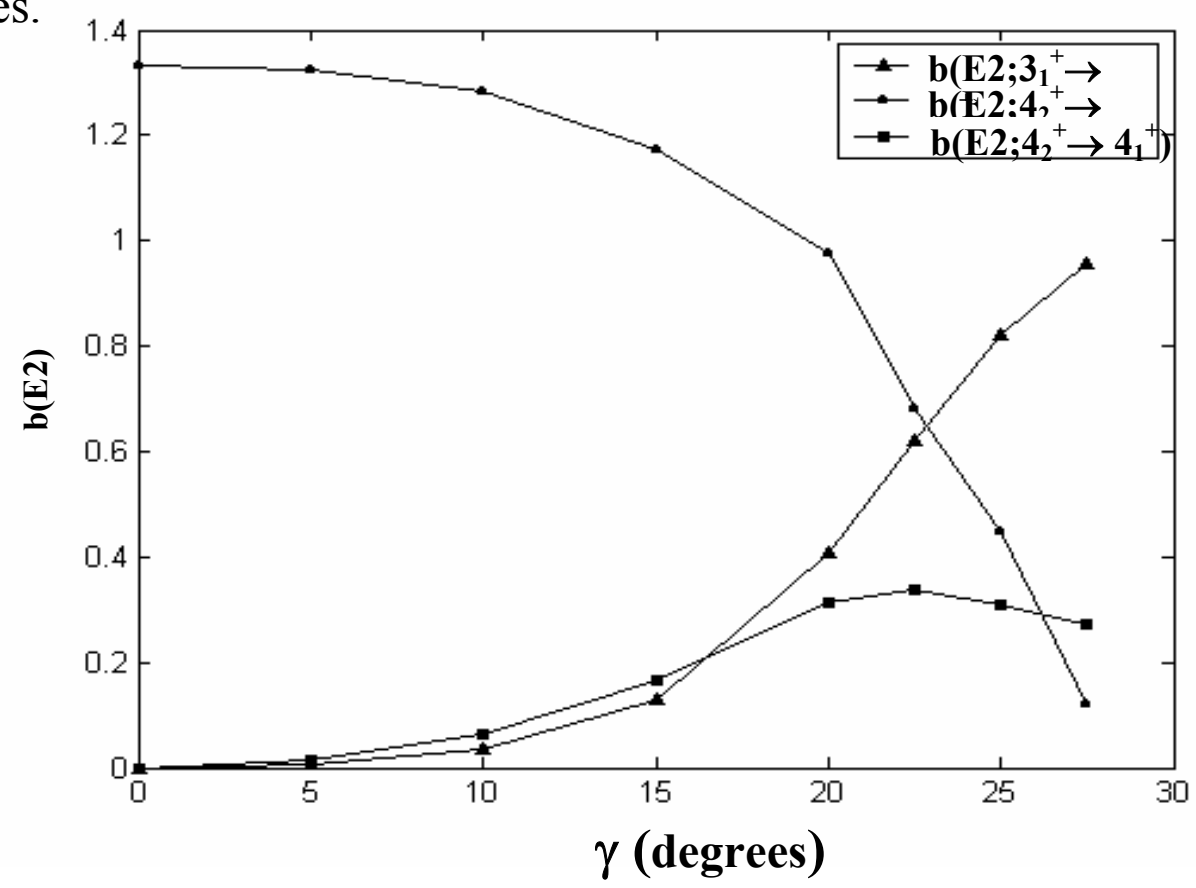

Fig (3): Reduced Transition Probabilities $b\left(E 2 ; 3_{1}{ }^{+} \rightarrow 4_{1}{ }^{\dagger}\right), b\left(E 2 ; 4_{2}{ }^{+} \rightarrow 3_{1}{ }^{+}\right)$and $\mathrm{b}\left(\mathrm{E} 2 ; \mathbf{4}_{2}{ }^{+} \rightarrow 4_{1}{ }^{+}\right)$, as a Function of $\gamma$-Values . 


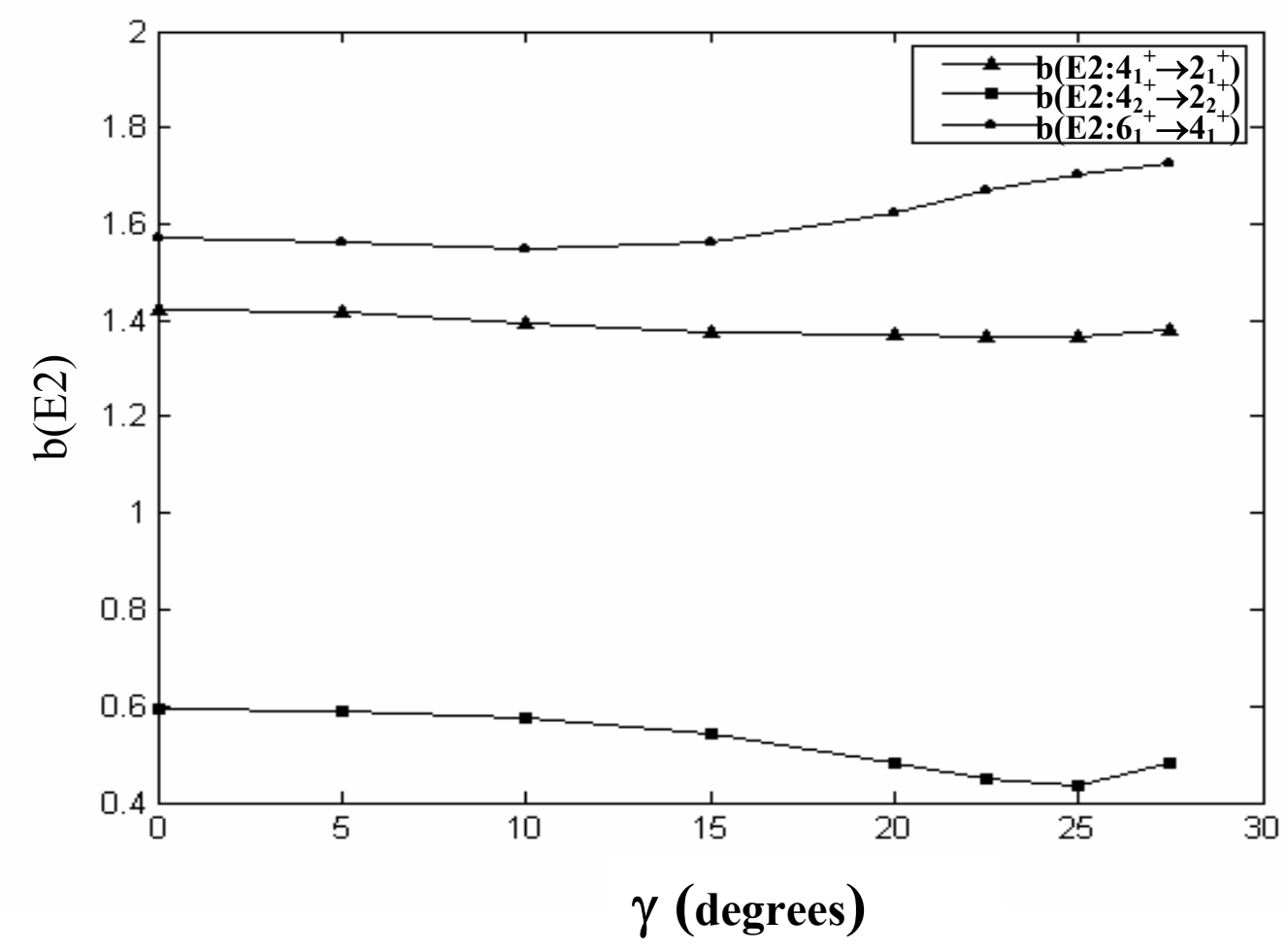

Fig(4): Reduced Transition probabilities $b\left(E 2 ; 4_{1}{ }^{+} \rightarrow 2_{1}{ }^{+}\right), \mathrm{b}\left(\mathrm{E} 2 ; 4_{2}{ }^{+} \rightarrow 2_{2}{ }^{+}\right)$and $\mathrm{b}\left(\mathrm{E} 2 ; \mathbf{6}_{1}{ }^{+} \rightarrow 4_{1}{ }^{+}\right)$as a Function of $\gamma$ Values.

Table (4): Calculated b(E2) Values From; (D-F) Model, Equation and graphical methods for ${ }^{146} \mathrm{Ba},{ }^{148} \mathrm{Ce},{ }^{158} \mathrm{Er}$ and ${ }^{160}$ Yb nuclei

\begin{tabular}{|c|c|c|c|c|}
\hline \multirow{2}{*}{$\mathrm{J}_{\mathrm{i}} \rightarrow \mathrm{J}_{\mathrm{f}}$} & \multicolumn{4}{|c|}{$\mathrm{b}(\mathrm{E} 2)$} \\
\cline { 2 - 5 } & ${ }^{146} \mathrm{Ba}$ & ${ }^{148} \mathrm{Ce}$ & ${ }^{158} \mathrm{Er}$ & ${ }^{160} \mathrm{Yb}$ \\
\hline $2_{1} \rightarrow 0_{1}$ & 0.94370 & 0.94242 & 0.934141 & 0.93384 \\
\hline $2_{2} \rightarrow 0_{1}$ & 0.05629 & 0.05758 & 0.06586 & 0.06616 \\
\hline $2_{2} \rightarrow 2_{1}$ & 0.16525 & 0.17478 & 0.28515 & 0.42750 \\
\hline $3_{1} \rightarrow 2_{1}$ & 0.10053 & 0.10282 & 0.11761 & 0.11815 \\
\hline $3_{1} \rightarrow 2_{2}$ & 1.68518 & 1.68289 & 1.66811 & 1.66757 \\
\hline $3_{1} \rightarrow 4_{1}$ & 0.15938 & 0.17206 & 0.31697 & 0.48726 \\
\hline $4_{1} \rightarrow 2_{1}$ & 1.37622 & 1.37598 & 1.37387 & 1.36975 \\
\hline $4_{2} \rightarrow 2_{2}$ & 0.50924 & 0.50788 & 0.49302 & 0.46786 \\
\hline $4_{2} \rightarrow 4_{1}$ & 0.19199 & 0.20185 & 0.28366 & 0.32962 \\
\hline $6_{1} \rightarrow 4_{1}$ & 1.56779 & 1.57036 & 1.60209 & 1.64241 \\
\hline
\end{tabular}




\section{3-2-4 Critical Point Symmetry X(5).}

The critical point symmetry $\mathrm{X}(5)$ has been used to calculate the reduced electric transition probability $\mathrm{B}(\mathrm{E} 2)$ for ${ }^{146} \mathrm{Ba},{ }^{148} \mathrm{Ce},{ }^{158} \mathrm{Er}$ and ${ }^{160} \mathrm{Yb}$ nuclei. The theoretical $\mathrm{B}(\mathrm{E} 2)$ values from critical point symmetry $\mathrm{X}(5)$ [(see Figure(1)] are fitted to the experimental $\mathrm{B}\left(\mathrm{E} 2 ; 2_{1}{ }^{+} \rightarrow 0_{1}{ }^{+}\right)$values of the above nuclei, and the other transition strengths are determined by using the conversion constants. The constants was calculated by dividing the $\mathrm{B}\left(\mathrm{E} 2 ; 2_{1}{ }^{+} \rightarrow 0_{1}{ }^{+}\right)_{\exp }$ obtained from (27-30) by the corresponding value obtained from $(3,5)$.

\section{4-Result and Discussion}

\section{4-1-Energy level}

The energy values of the low-lying positive parity states of ${ }^{146} \mathrm{Ba},{ }^{148} \mathrm{Ce},{ }^{158} \mathrm{Er}$ and ${ }^{160} \mathrm{Yb}$ nuclei calculated by the IBM-1, D-F models and critical point symmetry $\mathrm{X}(5)$ are compared with experimental values (27-30) as shown in Table(5). It can be seen from this table that the most of present results from IBM-1 calculations are in good agreement with the experimental energy levels values within the associated errors which are found to be less than $24 \%$ for all levels. It is obvious that the IBM-1 calculations give better values than those of D-F predictions, especially, for $4_{1}{ }^{+}, 4_{2}{ }^{+}, 6_{1}{ }^{+}$and $8_{1}{ }^{+}$states, in addition there is good agreement between experimental data and the theoretical energy levels calculated by $\mathrm{X}(5)$ limit, especially, for $2_{1}{ }^{+}, 4_{1}{ }^{+}, 6_{1}{ }^{+}$and $8_{1}{ }^{+}$states. The significant apparent discrepancy is that for $2_{3}{ }^{+}$state of ${ }^{146} \mathrm{Ba}, 2_{2}{ }^{+}, 2_{3}{ }^{+}$, and $3_{1}{ }^{+}$states of ${ }^{148} \mathrm{Ce}$, $0_{2}{ }^{+}, 2_{2}^{+}, 2_{3}{ }^{+}, 4_{2}{ }^{+}$and $3_{1}{ }^{+}$states of ${ }^{158} \mathrm{Er}$ and ${ }^{160} \mathrm{Yb}$ nuclei. Two basic predictions of the $\mathrm{X}(5)$ model are that $\mathrm{R}_{4 / 2}=2.91$ ( or $2.71 \leq \mathrm{R}_{4 / 2} \leq 3.11$ ) and $\mathrm{E}\left(0_{2}{ }^{+}\right) / \mathrm{E}\left(2_{1}{ }^{+}\right)=5.67(3,5)$. The $\mathrm{R}_{4 / 2}$ equal to $2.83,2.87,2.74$ and 2.63 and $\mathrm{E}\left(0_{2}{ }^{+}\right) / \mathrm{E}\left(2_{1}^{+}\right)$equal to $5.81,4.87,4.2$ and 4.47 for ${ }^{146} \mathrm{Ba},{ }^{148} \mathrm{Ce},{ }^{158} \mathrm{Er}$ and ${ }^{160} \mathrm{Yb}$ nuclei respectively. It is evident from Table (5) and the above ratios that the ${ }^{146} \mathrm{Ba}$ and ${ }^{148} \mathrm{Ce}$ nuclei have a structure near to the $\mathrm{X}(5)$ symmetry. One can be observe from Table (5) that the D-F model is not able to reproduce the $0_{2}{ }^{+}, \mathrm{O}_{3}{ }^{+}$and $2_{3}{ }^{+}$states. 
Table (5): Calculated Values of Energy Levels for ${ }^{146} \mathrm{Ba},{ }^{148} \mathrm{Ce},{ }^{158} \mathrm{Er}$ and ${ }^{160} \mathrm{Yb}$ nuclei Which Compared With Corresponding Experimental Data.

${ }^{146} \mathrm{Ba} \quad{ }^{148} \mathrm{Ce}$

\begin{tabular}{|c|c|c|c|c|c|c|c|c|c|c|c|c|c|c|c|}
\hline \multirow{2}{*}{$\mathbf{J}^{\pi}$} & \multirow{2}{*}{$\begin{array}{l}E_{\text {exp. }} \\
(\mathrm{MeV})\end{array}$} & \multicolumn{6}{|c|}{$\mathrm{E}_{\text {cal }}(\mathrm{MeV})$} & \multirow{2}{*}{$\mathbf{J}^{\pi}$} & \multirow{2}{*}{$\begin{array}{l}E_{\text {exp. }} \\
(\mathrm{MeV})\end{array}$} & \multicolumn{6}{|c|}{$\mathrm{E}_{\text {cal }}(\mathrm{MeV})$} \\
\hline & & IBM & $\Delta(\%)^{(a)}$ & $\begin{array}{l}\text { (D- } \\
\text { F) }\end{array}$ & $\Delta(\%)^{(a)}$ & $X(5)$ & $\Delta(\%)^{(\mathrm{a})}$ & & & IBM & $\Delta(\%)^{(a)}$ & (D-F) & $\Delta(\%)^{(a)}$ & $X(5)$ & $\Delta(\%)^{(a)}$ \\
\hline $2_{1}{ }^{+}$ & 0.181 & 0.151 & 16.6 & 0.181 & 0.0 & 0.181 & 0.0 & $2_{1}{ }^{+}$ & 0.158 & 0.130 & 17.7 & 0.158 & 0.0 & 0.158 & 0.0 \\
\hline $4_{1}{ }^{+}$ & 0.513 & 0.500 & 2.6 & 0.590 & -15.0 & 0.526 & -2.5 & $4_{1}^{+}$ & 0.453 & 0.434 & 4.2 & 0.514 & -13.5 & 0.459 & -1.3 \\
\hline $\mathrm{O}_{2}^{+}$ & 1.052 & 1.034 & 1.7 & & & 1.023 & 2.8 & $\mathrm{O}_{2}^{+}$ & 0.770 & 0.784 & -1.8 & & & 0.893 & -16.0 \\
\hline $6_{1}^{+}$ & 0.958 & 1.045 & -9.1 & 1.199 & -25.2 & 0.983 & -2.6 & $6_{1}^{+}$ & 0.839 & 0.910 & -8.5 & 1.043 & -24.3 & 0.858 & -2.3 \\
\hline $2_{2}^{+}$ & 1.115 & 1.224 & -9.8 & 1.115 & 0.0 & 1.348 & -20.9 & $2_{2}^{+}$ & 0.935 & 0.927 & 0.86 & 0.935 & 0.0 & 1.177 & -25.9 \\
\hline $2_{3}{ }^{+}$ & 1.256 & 1.356 & -8.0 & & & 1.810 & -44.1 & $2_{3}^{+}$ & 0.989 & 1.013 & -2.4 & & & 1.580 & -59.6 \\
\hline $8_{1}^{+}$ & 1.482 & 1.784 & -20.4 & 1.973 & -33.1 & 1.535 & -3.6 & $8_{1}{ }^{+}$ & 1.290 & 1.558 & -20.8 & 1.710 & -32.6 & 1.340 & -3.9 \\
\hline $4_{2}^{+}$ & & 1.623 & & 1.558 & & 1.935 & & $4_{2}^{+}$ & 1.224 & 1.252 & -2.2 & 1.323 & -8.1 & 1.689 & -38.0 \\
\hline $3_{1}^{+}$ & & 1.530 & & 1.296 & & 1.980 & & $3_{1}^{+}$ & 1.116 & 1.151 & -3.1 & 1.093 & 2.1 & 1.729 & -54.9 \\
\hline
\end{tabular}

${ }^{158} \mathrm{Er}$

${ }^{160} \mathrm{Yb}$

\begin{tabular}{|c|c|c|c|c|c|c|c|c|c|c|c|c|c|c|c|}
\hline \multirow{2}{*}{$\mathbf{J}^{\pi}$} & \multirow{2}{*}{$\begin{array}{l}E_{\text {exp. }} \\
(\mathrm{MeV})\end{array}$} & \multicolumn{6}{|c|}{$\mathrm{E}_{\text {cal }}(\mathrm{MeV})$} & \multirow{2}{*}{$\mathbf{J}^{\pi}$} & \multirow{2}{*}{$\begin{array}{l}E_{\text {exp. }} \\
(\mathrm{MeV})\end{array}$} & \multicolumn{6}{|c|}{$\mathrm{E}_{\mathrm{cal} \cdot}(\mathrm{MeV})$} \\
\hline & & IBM & $\Delta(\%)^{(a)}$ & (D-F) & $\Delta(\%)^{(a)}$ & $X(5)$ & $\Delta(\%)^{(\mathrm{a})}$ & & & IBM & $\Delta(\%)^{(a)}$ & (D-F) & $\Delta(\%)^{(a)}$ & $X(5)$ & $\Delta(\%)^{(\mathrm{a})}$ \\
\hline $2_{1}^{+}$ & 0.192 & 0.15 & 21.9 & 0.192 & 0.0 & 0.192 & 0.0 & $2_{1}{ }^{+}$ & 0.243 & 0.193 & 20.6 & 0.243 & 0.0 & 0.243 & 0.0 \\
\hline $4_{1}^{+}$ & 0.527 & 0.500 & 5.1 & 0.609 & -15.6 & 0.558 & -5.9 & $4_{1}^{+}$ & 0.638 & 0.623 & 2.4 & 0.746 & -16.8 & 0.706 & -10.7 \\
\hline $\mathrm{O}_{2}^{+}$ & 0.806 & 0.718 & 10.8 & & & 1.085 & -34.6 & $\mathrm{O}_{2}^{+}$ & 1.086 & 0.922 & 15.1 & & & 1.373 & -26.4 \\
\hline $6_{1}{ }^{+}$ & 0.970 & 1.048 & -8.0 & 1.202 & -23.9 & 1.043 & -7.5 & $6_{1}{ }^{+}$ & 1.147 & 1.276 & -11.2 & 1.437 & -25.3 & 1.319 & -15.0 \\
\hline $2_{2}^{+}$ & 0.820 & 0.885 & -7.6 & 0.820 & 0.0 & 1.430 & $-74,4$ & $2_{2}^{+}$ & 0.820 & 0.954 & -16.3 & 0.820 & 0.0 & 1.810 & -120.7 \\
\hline $2_{3}{ }^{+}$ & 0.989 & 1.035 & -4.7 & & & 1.920 & -94.1 & $2_{3}{ }^{+}$ & 1.293 & 1.272 & 1.6 & & & 2.43 & -87.9 \\
\hline $8_{1}{ }^{+}$ & 1.493 & 1.793 & -20.0 & 1.942 & -30.0 & 1.629 & -9.1 & $8_{1}{ }^{+}$ & 1.736 & 2.144 & -23.5 & 2.319 & -33.6 & 2.061 & -18.7 \\
\hline $4_{2}^{+}$ & 1.184 & 1.263 & -6.7 & 1.310 & -10.6 & 2.052 & -73.3 & $4_{2}^{+}$ & 1.529 & 1.451 & 5.1 & 1.477 & 3.4 & 2.598 & -69.9 \\
\hline $\mathrm{O}_{3}^{+}$ & 1.387 & 1.256 & 9.4 & & & & & $3_{1}{ }^{+}$ & 1.113 & 1.224 & -9.9 & 1.063 & 4.5 & 2.658 & -138.8 \\
\hline $3_{1}{ }^{+}$ & 1.043 & 1.196 & -14.7 & 1.012 & 2.97 & 2.100 & -101.3 & & & & & & & & \\
\hline
\end{tabular}




\section{4-2 Reduced Transition Probabilities}

The absolute experimental Reduced transition probabilities $\mathrm{B}(\mathrm{E} 2)$ and the relative $\mathrm{B}(\mathrm{E} 2)$ values for ${ }^{146} \mathrm{Ba},{ }^{148} \mathrm{Ce},{ }^{158} \mathrm{Er}$ and ${ }^{160} \mathrm{Yb}$ nuclei have been calculated from the available experimental data (27-30) and compared with those predicted by the IBM-1, D-F models and critical point symmetry $\mathrm{X}(5)$ is shown in Table (6). An inspection of this table shows that there is, in general, good agreement between the experimental $\mathrm{B}(\mathrm{E} 2)$ values for all the transitions and those from IBM-1 calculations except for $2_{3}{ }^{+} \rightarrow 4_{1}{ }^{+}, 3_{1}{ }^{+} \rightarrow 2_{1}{ }^{+}$transitions of ${ }^{148} \mathrm{Ce}, 2_{3}{ }^{+} \rightarrow 2_{1}{ }^{+}, 2_{3}{ }^{+} \rightarrow 0_{1}{ }^{+}$, $3_{1}{ }^{+} \rightarrow 4_{1}{ }^{+}, 3_{1}{ }^{+} \rightarrow 2_{1}{ }^{+}, 4_{2}{ }^{+} \rightarrow 4_{1}{ }^{+}$transitions of ${ }^{158} \mathrm{Er}, 3_{1}{ }^{+} \rightarrow 4_{1}{ }^{+}$and $2_{3}{ }^{+} \rightarrow 2_{1}{ }^{+}$ transitions of ${ }^{160} \mathrm{Yb}$. It can also be remarked that the D-F calculations gives acceptable agreement with the experimental $\mathrm{B}(\mathrm{E} 2)$ values for all the transitions except for $3_{1}{ }^{+} \rightarrow 4_{1}{ }^{+}, 3_{1}{ }^{+} \rightarrow 2_{1}{ }^{+}, 4_{2}{ }^{+} \rightarrow 4_{1}{ }^{+}$transitions of ${ }^{158} \mathrm{Er}$ and $3_{1}{ }^{+} \rightarrow 2_{1}{ }^{+}$transition of ${ }^{160} \mathrm{Yb}$. The $\mathrm{B}(\mathrm{E} 2)$ values are well reproduced by the $\mathrm{X}(5)$ calculations. The significant apparent discrepancy is that for $0_{2}{ }^{+} \rightarrow 2_{1}^{+}$transition of ${ }^{146} \mathrm{Ba}, 2_{2}{ }^{+} \rightarrow 2_{1}{ }^{+}, 2_{3}{ }^{+} \rightarrow 4_{1}{ }^{+}, 3_{1}{ }^{+} \rightarrow 2_{1}{ }^{+}$transitions of ${ }^{148} \mathrm{Ce}$ and most of the transitions depopulated the $2{ }_{3}^{+}, 3_{1}{ }^{+}$and $4_{2}{ }^{+}$states of ${ }^{158} \mathrm{Er}$ and ${ }^{160} \mathrm{Yb}$ nuclei are higher than the experimental values. Most of the experimental $\mathrm{B}(\mathrm{E} 2)$ values for ${ }^{146} \mathrm{Ba}$ and ${ }^{148} \mathrm{Ce}$ nuclei are close to $\mathrm{X}(5)$ symmetry.

Table (6): Comparison of Experimental and Theoretical B(E2) Values for ${ }^{146} \mathrm{Ba},{ }^{148} \mathrm{Ce},{ }^{158} \mathrm{Er}$ and ${ }^{160} \mathrm{Yb}$ nuclei .

${ }^{146} \mathrm{Ba} \quad{ }^{160} \mathrm{Yb}$

\begin{tabular}{|c|c|c|c|c|c|c|c|c|c|c|c|c|c|}
\hline \multirow{2}{*}{$\begin{array}{c}E_{i} \\
(\mathrm{MeV})\end{array}$} & \multirow{2}{*}{$\begin{array}{c}E_{\gamma} \\
(\mathrm{MeV})\end{array}$} & \multirow{2}{*}{$\mathbf{J}_{i}^{\pi} \rightarrow \mathbf{J}_{\mathbf{f}}^{\pi}$} & \multirow{2}{*}{$\frac{B(E 2)_{\text {exp. }}}{\left(\mathrm{e}^{2} b^{2}\right)^{2}}$} & \multicolumn{3}{|c|}{$B(E 2)_{\text {theo. }}\left(e^{2} b^{2}\right)$} & \multirow{2}{*}{$\begin{array}{c}E_{i} \\
(\mathrm{MeV})\end{array}$} & \multirow{2}{*}{$\begin{array}{c}E_{\gamma} \\
(\mathrm{MeV})\end{array}$} & \multirow{2}{*}{$\mathbf{J}_{i}^{\pi} \rightarrow \mathbf{J}_{f}^{\pi}$} & \multirow{2}{*}{$\begin{array}{c}\mathrm{B}(\mathrm{E} 2)_{\exp } \\
\left(\mathrm{e}^{2} \mathbf{b}^{2}\right)\end{array}$} & \multicolumn{3}{|c|}{$B(E 2)_{\text {theo. }}\left(e^{2} b^{2}\right)$} \\
\hline & & & & $\begin{array}{l}\text { IBM- } \\
1\end{array}$ & D-F & $X(5)$ & & & & & IBM-1 & D-F & $X(5)$ \\
\hline 0.181 & 0.181 & $2_{1}{ }^{+} \rightarrow 0_{1}{ }^{+}$ & 0.272 & 0.272 & 0.272 & 0.272 & 0.243 & 0.243 & $2_{1}{ }^{+} \rightarrow 0_{1}{ }^{+}$ & 0.481 & 0.481 & 0.481 & 0.481 \\
\hline 0.514 & 0.332 & $4_{1}^{+} \rightarrow 2_{1}{ }^{+}$ & 0.751 & 0.374 & 0.397 & 0.435 & 0.638 & 0.395 & $4_{1}{ }^{+} \rightarrow 2_{1}{ }^{+}$ & 0.6664 & 0.6909 & 0.7051 & 0.769 \\
\hline $\begin{array}{c}0.958 \\
\text { a) }\end{array}$ & 0.445 & $6_{1}{ }^{+} \rightarrow 4_{1}{ }^{+}$ & 1.0 & 1.0 & 1.0 & 1.0 & $0.820^{\text {a) }}$ & 0.577 & $2_{2}^{+} \rightarrow 2_{1}{ }^{+}$ & 1.0 & 1.0 & 1.0 & 1.0 \\
\hline 1.053 & 0.871 & $\mathbf{0}_{2}{ }^{+} \rightarrow \mathbf{2}_{1}{ }^{+}$ & $>0.0043$ & 0.007 & & 0.169 & & 0.820 & $\mathbf{2}_{2}{ }^{+} \rightarrow 0_{1}{ }^{+}$ & 0.098 & 0.124 & 0.1548 & 0.256 \\
\hline \multirow[t]{3}{*}{$\frac{1.115}{\text { a) }}$} & 0.934 & $2_{2}^{+} \rightarrow 2_{1}^{+}$ & 1.0 & 1.0 & 1.0 & 1.0 & $1.113^{\text {a) }}$ & 0.293 & $3_{1}{ }^{+} \rightarrow 2_{2}{ }^{+}$ & 1.0 & 1.0 & 1.0 & 1.0 \\
\hline & \multirow{2}{*}{1.115} & \multirow{2}{*}{$2_{2}^{+} \rightarrow 0_{1}^{+}$} & \multirow{2}{*}{0.317} & \multirow{2}{*}{0.294} & \multirow{2}{*}{0.341} & \multirow{2}{*}{0.256} & & 0.474 & $3_{1}{ }^{+} \rightarrow 4_{1}{ }^{+}$ & 0.1 & 0.0233 & 0.292 & 6.395 \\
\hline & & & & & & & & 0.870 & $3_{1}{ }^{+} \rightarrow 2_{1}{ }^{+}$ & 0.0269 & 0.0166 & 0.071 & 15.158 \\
\hline \multirow[t]{3}{*}{$\begin{array}{l}1.256 \\
\text { a) }\end{array}$} & 1.075 & $23^{+} \rightarrow 2_{1}{ }^{+}$ & 1.0 & 1.0 & 1.0 & 1.0 & 1.147 & 0.509 & $6_{1}{ }^{+} \rightarrow 4_{1}{ }^{+}$ & 0.8609 & 0.7527 & 0.846 & 0.952 \\
\hline & & & & & & & $1.293^{\text {a) }}$ & 0.654 & $2_{3}{ }^{+} \rightarrow 4_{1}{ }^{+}$ & 1.0 & 1.0 & & 1.0 \\
\hline & 1.256 & $2_{3}{ }^{+} \rightarrow 0_{1}{ }^{+}$ & 0.793 & 0.8 & ----- & 0.667 & & 1.050 & $2_{3}{ }^{+} \rightarrow 2_{1}{ }^{+}$ & 0.5856 & 0.154 & & 19.042 \\
\hline \multirow[t]{2}{*}{1.482} & \multirow[t]{2}{*}{0.524} & \multirow{2}{*}{$8_{1}{ }^{+} \rightarrow 6_{1}{ }^{+}$} & \multirow[t]{2}{*}{1.0} & \multirow[t]{2}{*}{1.0} & \multirow[t]{2}{*}{1.0} & \multirow[t]{2}{*}{1.0} & & 1.293 & $2_{3}^{+} \rightarrow 0_{1}^{+}$ & 0.1262 & 0.133 & & 12.694 \\
\hline & & & & & & & 1.736 & 0.589 & $8_{1}{ }^{+} \rightarrow 6_{1}{ }^{+}$ & 0.787 & 0.761 & & 1.096 \\
\hline
\end{tabular}

a) Relative method 
${ }^{148} \mathrm{Ce}$

${ }^{158} \mathrm{Er}$

\begin{tabular}{|c|c|c|c|c|c|c|c|c|c|c|c|c|c|}
\hline \multirow{2}{*}{$\begin{array}{c}E_{i} \\
(\mathrm{MeV})\end{array}$} & \multirow{2}{*}{$\begin{array}{c}E_{\mathrm{y}} \\
(\mathrm{MeV})\end{array}$} & \multirow{2}{*}{$\mathbf{J}_{i}^{\pi} \rightarrow \mathbf{J}_{\mathbf{f}}^{\pi}$} & \multirow{2}{*}{$\begin{array}{c}\mathrm{B}(\mathrm{E} 2)_{\exp } \\
\left(\mathbf{e}^{2} \mathbf{b}^{2}\right)\end{array}$} & \multicolumn{3}{|c|}{$B(E 2)_{\text {theo. }}\left(e^{2} b^{2}\right)$} & \multirow{2}{*}{$\begin{array}{c}E_{i} \\
(\mathrm{MeV})\end{array}$} & \multirow{2}{*}{$\begin{array}{c}E_{\gamma} \\
(\mathrm{MeV})\end{array}$} & \multirow{2}{*}{$\mathbf{J}_{\mathbf{i}}^{\pi} \rightarrow \mathbf{J}_{\mathbf{f}}^{\pi}$} & \multirow{2}{*}{$\begin{array}{l}B(E 2)_{\exp } \\
\left(\mathrm{e}^{2} \mathbf{b}^{2}\right)\end{array}$} & \multicolumn{3}{|c|}{$B(E 2)_{\text {theo. }}\left(e^{2} b^{2}\right)$} \\
\hline & & & & IBM-1 & D-F & $X(5)$ & & & & & IBM-1 & D-F & $X(5)$ \\
\hline 0.158 & 0.158 & $2_{1}{ }^{+} \rightarrow 0_{1}{ }^{+}$ & 0.397 & 0.397 & 0.397 & 0.397 & 0.192 & 0.192 & $2{ }_{1}{ }^{+} \rightarrow 0_{1}{ }^{+}$ & 0.6518 & 0.6519 & 0.6518 & 0.6518 \\
\hline $0.453^{a)}$ & 0.295 & $4_{1}{ }^{+} \rightarrow 2_{1}{ }^{+}$ & 1.0 & 1.0 & 1.0 & 1.0 & 0.527 & 0.335 & $\mathbf{4}_{1}{ }^{+} \rightarrow \mathbf{2}_{1}{ }^{+}$ & 0.945 & 0.9176 & 0.9586 & 1.0429 \\
\hline $0.770^{\text {a) }}$ & 0.612 & $\mathbf{0}_{2}^{+} \rightarrow \mathbf{2}_{1}^{+}$ & 1.0 & 1.0 & & 1.0 & $0.806^{\text {a) }}$ & 0.614 & $\mathbf{0}_{2}{ }^{+} \rightarrow \mathbf{2}_{1}{ }^{+}$ & 1.0 & 1.0 & & 1.0 \\
\hline $0.839^{\text {a) }}$ & 0.386 & $6_{1}{ }^{+} \rightarrow 4_{1}{ }^{+}$ & 1.0 & 1.0 & 1.0 & 1.0 & $0.820^{\text {a) }}$ & 0.628 & $\mathbf{2}_{2}{ }^{+} \rightarrow 2_{1}{ }^{+}$ & 1.0 & 1.0 & 1.0 & 1.0 \\
\hline \multirow[t]{2}{*}{$0.936^{\text {a) }}$} & 0.482 & $2_{2}^{+} \rightarrow 4_{1}{ }^{+}$ & 1.0 & 1.0 & & 1.0 & & 0.820 & $\mathbf{2}_{2}{ }^{+} \rightarrow 0_{1}{ }^{+}$ & 0.129 & 0.44 & 0.231 & 0.256 \\
\hline & 0.777 & $2_{2}{ }^{+} \rightarrow 2_{1}{ }^{+}$ & 0.707 & 0.38 & & 0.22 & 0.970 & 0.443 & $6_{1}{ }^{+} \rightarrow 4_{1}{ }^{+}$ & 1.2477 & 0.9825 & 1.1179 & 1.291 \\
\hline \multirow[t]{3}{*}{$0.989^{\text {a) }}$} & 0.536 & $2_{3}{ }^{+} \rightarrow 4_{1}{ }^{+}$ & 0.862 & 0.111 & & 0.053 & $0.989^{\text {a) }}$ & 0.182 & $2_{3}{ }^{+} \rightarrow 0_{2}^{+}$ & 1.0 & 1.0 & & 1.0 \\
\hline & 0.831 & $\mathbf{2}_{3}{ }^{+} \rightarrow \mathbf{2}_{1}{ }^{+}$ & 1.0 & 1.0 & & 1.0 & & 0.462 & $2_{3}{ }^{+} \rightarrow 4_{1}{ }^{+}$ & 0.082 & 0.104 & & 0.8845 \\
\hline & 0.989 & $2_{3}{ }^{+} \rightarrow 0_{1}{ }^{+}$ & 0.76 & 0.667 & & 0.667 & & 0.797 & $\mathbf{2}_{3}{ }^{+} \rightarrow \mathbf{2}_{1}{ }^{+}$ & 0.0072 & 0.79 & & 16.846 \\
\hline \multirow[t]{3}{*}{$1.117^{\mathrm{a})}$} & 0.663 & $3_{1}{ }^{+} \rightarrow 4_{1}{ }^{+}$ & 1.0 & 1.0 & 1.0 & 1.0 & & 0.989 & $2_{3}{ }^{+} \rightarrow 0_{1}{ }^{+}$ & 0.0078 & 0.5 & & 11.23 \\
\hline & 0.958 & $3_{1}{ }^{+} \rightarrow 2_{1}{ }^{+}$ & 0.418 & 1.429 & 0.598 & 237 & $1.043^{\text {a) }}$ & 0.223 & $3_{1}{ }^{+} \rightarrow 2_{2}{ }^{+}$ & 1.0 & 1.0 & 1.0 & 1.0 \\
\hline & & & & & & & & 0.516 & $3{ }_{1}{ }^{+} \rightarrow 4_{1}{ }^{+}$ & 0.087 & 0.29 & 0.19 & 6.395 \\
\hline $1.224^{\text {a) }}$ & 0.771 & $4_{2}{ }^{+} \rightarrow 4_{1}^{+}$ & 1.0 & 1.0 & 1.0 & 1.0 & & 0.851 & $3_{1}{ }^{+} \rightarrow 2_{1}{ }^{+}$ & 0.0282 & 0.45 & 0.0705 & 15.1578 \\
\hline \multirow{3}{*}{$1.290^{\text {a) }}$} & & & & & & & $1.183^{\text {a) }}$ & 0.364 & $4_{2}{ }^{+} \rightarrow 2_{2}{ }^{+}$ & 1.0 & 1.0 & 1.0 & 1.0 \\
\hline & 0.451 & $8{ }_{1}{ }^{+} \rightarrow 6_{1}{ }^{+}$ & 1.0 & 1.0 & 1.0 & 1.0 & & 0.657 & $4_{2}{ }^{+} \rightarrow 4_{1}{ }^{+}$ & 0.1673 & 0.0075 & 0.56 & 6.946 \\
\hline & & & & & & & 1.493 & 0.523 & $8{ }_{1}{ }^{+} \rightarrow 6_{1}{ }^{+}$ & 1.5135 & 0.9839 & & 1.486 \\
\hline
\end{tabular}

\section{5- Conclusions}

1- The results from IBM-1 calculations are in good agreement with the experimental values between the SU(5) and SU(3) limits. .

2- The theoretical energy values for $6_{1}^{+}$and $8_{1}^{+}$states obtained from D$\mathrm{F}$ model are higher than the experimental data. The D-F model is not able to reproduce the $\mathrm{O}_{2}{ }^{+}, \mathrm{O}_{3}{ }^{+}$and $2_{3}{ }^{+}$states.

3- ${ }^{146} \mathrm{Ba}$ and ${ }^{148} \mathrm{Ce}$ nuclei are proposed as a possible examples of $\mathrm{X}(5)$ symmetry.

4- More experimental investigation on ${ }^{146} \mathrm{Ba},{ }^{148} \mathrm{Ce},{ }^{158} \mathrm{Er}$ and ${ }^{160} \mathrm{Yb}$ level Schemes are required in order to identify the absolute $B(E 2)$ strengths. 


\section{References}

1. Zamfir N. V., Casten R. F., Caprio M. A., Beausang C. W., Krucken R., Novak J. R., Cooper J. R., Cata-Danil G. and Barton C. J., Physical Review C 60:054312(11) (1999).

2. Iachallo F, Phys. Rev. letter, Vol.87: Number 5, 052502(4) (2001).

3. Caprio M. A., Ph.D Thesis. Yale university (2003).

4. Casten R.F., Zamfir N.V. and Kruchen R., Physical Review C 68: 059801 (2003).

5. Bijker R., Casten, R. F., Zamfir, N. V. and Mecutchan, E. A., From CONACYT, Mexico, and by USDOE Crant NO. DE-FG02-91ER40609, (1-8), (2004).

6. Scholten O., Iachello F. and Arima A., Ann. Phys. 115:325-366 (1978).

7. Iachallo F. and Arima A., "The Interacting Boson Model". Combridge University Press (1987).

8. Iachello F., Zamfir N.V. and Casten R.F., Physical Review Letters, Volume 81: Number 6,1191-1194 (1998).

9. Krucken R., Albanna B., Bialik C., Casten R.F., Cooper J.R., Dewald A., Zamfir N.V., Barton C.J., Beausang C.W., Caprio M.A., Hecht A.A., Klug T., Novak J.R., Pietralla N., and von Brentano P., Physical Review Letters, Volume 88: Number 23, 232501(4) (2002).

10. Clark R.M., Cromaz M., Deleplanque M.A., Diamond R.M., Fallon P., Gorgen A., Lee I.Y., Macchiavelli A.O., Stephens F.S. and Ward D., Physical Review C 67: 041302(5) (2003).

11. McCutchan E.A., Zamfir N.V., Caprio M.A., Casten R.F., Amro H., Beausang C.W., Brenner D.S., Hecht A.A., Hutter C., Langdown S.D., Meyer D.A., Regan P.H., Ressler J.J. and Yamamoto A.D., Physical Review C 69: 024308(10) (2004).

12. Arima A., Iachallo F., Ann. Phys.Vol.99: 253-317 (1976).

13. Arima A., Iachallo F., Ann. Phys. Vol.111: 201-238 (1978).

14. Arima A., Iachallo F., Ann. Phys. Vol.123: 468-492 (1979). 
15. Iachallo F., "An Introduction to the Interacting Boson Model Nuclear structure", Edited by Abrahams K., Alleart K. and Dieperink A. E.L., Plenum Press (1980).

16. Pfeifer W., "An Introduction to the Interacting Boson Model of the Atomic Nucleus "ISBN 3-7281-2520-2 (1988).

17. Casten R.F. and Warner D.D. ,Rev. Mod. Phys. Vol. 60: No.2, 389469 (1988).

18. Davydov A. S. and Filippov G. F., Nucl. Physics Vol. 8: 237249(1958).

19. Davydov A.S and Rostovsky V. S., Nucl. Phys. 12: 58-68 (1959).

20. Grigoriev E.P. and Avotina M.P., Nucl.Phys.10:248-263(1960).

21. Wahed S.S.N. M.Sc. Thesis. College of Education, University of Mosul (2005).

22. Mustafa M. Eb, M.Sc. Thesis. College of Education, University of Mosul (2005).

23. Abdulla H.Y M.Sc. Thesis. College of Education, University of Salahaddin (2002).

24. Iachallo F., Phys. Rev.lett., Vol. 85: Number 17, 3580-3583 (2000).

25. Firestone R.B. and Baglin., "Table of Isotopes" C.M. eighth edition, John wiley and Sons (1999).

26. Scholten O., "The Program Package PHINT" (Kerfysisch Versneller Institute Gronigor) KVI-63 (1979).

27. Peker L. K. and Tuli J. K., "Nuclear Data Sheets". Vol.82: 187 (1997).

28. Bhat M.R., "Nuclear Data Sheets", Vol.89: 797(2000).

29. Helmer R.G., "Nuclear Data Sheets", Vol.101: 325 (2004).

30. Reich C.W., "Nuclear Data Sheets", Vol.78: 547 (1996).

31. Rosel F., Fries. H.M., Alder. K., Pauli H. "Table of Internal Conversion Coefficients", Vol.21: No. 2,3, 91-289 (1978).

32. Venkova Ts and Andrejtscheff W., "At Data Nucl Data Tables", 26, 93 (1981). 